\title{
Blue toe syndrome, ischemic pain treated with digital block
}

\author{
Justin Belsky $\cdot$ Heidi Alvey $\cdot$ Alexis Bencze $\cdot$ \\ Brooke Thompson $\cdot$ Stephanie Stokes-Buzzelli
}

Received: 9 December 2014 / Accepted: 6 January 2015/Published online: 21 January 2015

(C) SIMI 2015

A 61-year-old man presented to the emergency department (ED) complaining of right great toe pain and worsening blue discoloration for 8 days. The patient was afebrile, and the remaining vital signs were normal. Physical examination was notable for symmetric and palpable posterior tibial and dorsalis pedis pulses with a mottled and cyanotic right great toe (Fig. 1). Ankle brachial pressure index on the right measured 1.1, and on the left was 1.2 (both normal range). Toe pressures were $0 \mathrm{mmHg}$ on the right great toe, $104 \mathrm{mmHg}$ on the right second toe, and $114 \mathrm{mmHg}$ on the left great toe. An EKG displayed a sinus rhythm, and a CT angiography of the abdomen and pelvis with three-vessel runoff revealed a fusiform, infrarenal, abdominal aortic aneurysm measuring $5.2 \mathrm{~cm} \times 5.5 \mathrm{~cm} \times 8.3 \mathrm{~cm}$, with a mural thrombus that extended into the right common iliac artery. The patient's toe pain was not relieved with intravenous narcotics; therefore, a digital block with $1 \%$ lidocaine was performed, which temporarily alleviated his pain completely.

Blue toe syndrome is the isolated development of a blue discoloration to one or more toes not caused by coldinduced injury or obvious trauma [1]. It is characterized by a cyanotic digit with an otherwise warm and well perfused

J. Belsky (凹)

Department of Emergency Medicine, Massachusetts General Hospital, Harvard Medical School, Boston, MA, USA

e-mail: jbelsky@partners.org

H. Alvey $\cdot$ A. Bencze $\cdot$ S. Stokes-Buzzelli

Department of Emergency Medicine, Henry Ford Hospital, Detroit, MI, USA

B. Thompson

Department of Emergency Medicine, Hurley Medical Center, Flint, MI, USA foot [2]. Blue toe syndrome is typically caused by microemboli that occlude small vessels; however, other nonembolic etiologies have also been described [3]. In our patient, the cause of his blue toe was suspected to be from embolic material dislodged from a thrombus present in his abdominal aortic aneurysm. $85 \%$ of athero-embolizations arise from aorto-illiac occlusive or aneurysmal disease [4]. Thus the isolated finding of a blue toe warrants further investigation with a CT angiography of the abdomen and pelvis to rule out significant stenosis or aneurysmal disease.

The mainstay of treatment is early identification, and removal of the embolic source [4]. Despite source control, patients are at increased risk of future embolic events, limb amputations, and death [5]. The management for removal of a mobile aortic mural thrombus includes medical treatment with anticoagulation, thrombolysis, thrombectomy, or endovascular exclusion with a stent graft; however, no consensus has been reached [6, 7]. Controversy arises over the use of antiplatelet, anticoagulation, and thrombolytic drugs in Blue Toe Syndrome as these have been shown to be ineffective, and may predispose patients to further atheroembolism events. [4, 8-10].

Given that the patient had palpable posterior tibial and dorsalis pedis pulses as well as a normal ankle brachial index, the vascular surgery team decided against amputation of the patient's toe. He was taken to the operating room, and underwent an endovascular abdominal aortic aneurysm repair with angioplasty. In our patient, the stent served not only as treatment for his abdominal aortic aneurysm, but also to exclude or cage off the thrombus material between the stent and vessel wall, effectively trapping it from systemic spread. He was discharged on aspirin, a home medication for secondary prevention of a previous myocardial infarction. At his 6-month post-operative visit, the patient's toe pain, claudication, and 


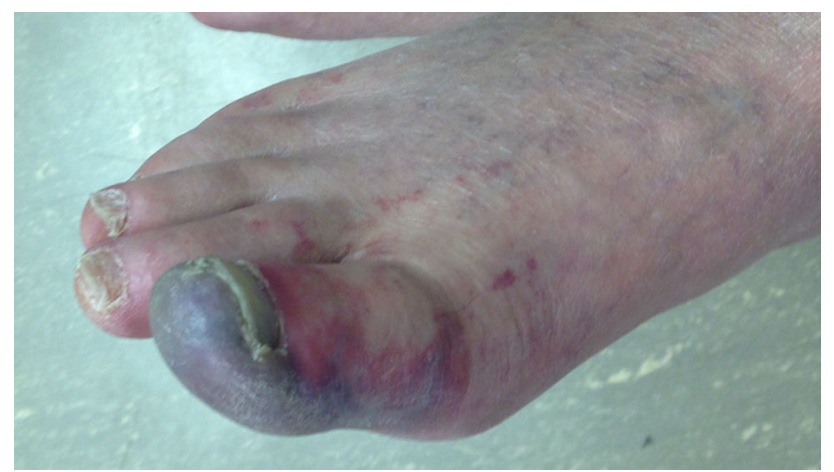

Fig. 1 Right great toe with blue discoloration

discoloration had resolved, and a repeat right great toe pressure was $106 \mathrm{mmHg}$.

In conclusion, we present the case of a male with blue toe syndrome who had digital pain unresponsive to intravenous narcotics. We report that a digital block was safe and effective in controlling his pain. The embolic source was localized to a thrombus present in his abdominal aortic aneurysm, and both the aneurysm and thrombus was successfully treated with an endovascular approach with resolution of his toe pain at his 6-month post-operative visit.

Conflict of interest None.

\section{References}

1. Hirschmann J, Raugi G (2009) Blue (or purple) toe syndrome. J Am Acad Dermatol 60:1-20

2. Karmody AM, Powers SR, Monaco VJ et al (1976) 'Blue toe' syndrome an indication for limb salvage surgery. Arch Surg 111:1263-1268

3. O'Keeffe S, Woods B, Breslin D et al (1992) Blue toe syndrome causes and management. Arch Int Med 152:2197-2202

4. Keen RR, McCarthy WJ, Shireman PK et al (1995) Surgical management of atheroembolization. J Vasc Surg 21:773-780

5. Matchett WJ, McFarland DR, Eidt JF et al (2000) Blue toe syndrome: treatment with intra-arterial stents and review of therapies. J Vasc Interv Radiol 11:585-592

6. Boufi M, Mameli A, Compes P et al (2014) Elective stent-grant treatment for the management of thoracic aorta mural thrombus. Eur J Vasc Endovasc Surg 47:335-341

7. Criado E, Wall P, Lucas P et al (2004) Transesophageal echoguided endovascular exclusion of thoracic aortic mobile thrombi. J Vasc Surg 39:238-242

8. Meyrier A (2006) Cholesterol crystal embolism: diagnosis and treatment. Kidney Int 69:1308-1312

9. Sawalhi S, Hamad H (2012) Etiology of 'blue toe' syndrome: emboli versus warfarin therapy. Report of a case. J Taibah Univ Med Sci 7:41-44

10. Hitti W, Wali R, Weiman E (2008) Cholesterol embolism syndrome induced by thrombolytic therapy. Am J Cardiovasc Drugs $8: 27-34$ 